\title{
Respiratory muscle ultrasonography: methodology, basic and advanced principles and clinical applications in ICU and ED patients-a narrative review
}

\author{
Pieter R. Tuinman 1,2, Annemijn H. Jonkman ${ }^{1}$, Martin Dres ${ }^{3}$, Zhong-Hua Shi ${ }^{1,4}$, Ewan C. Goligher ${ }^{5,6}$, \\ Alberto Goff5 ${ }^{5,7}$, Chris de Korte ${ }^{8}$, Alexandre Demoule ${ }^{3}$ and Leo Heunks ${ }^{1 *}$ (])
}

(C) 2020 The Author(s)

\begin{abstract}
Respiratory muscle ultrasound is used to evaluate the anatomy and function of the respiratory muscle pump. It is a safe, repeatable, accurate, and non-invasive bedside technique that can be successfully applied in different settings, including general intensive care and the emergency department. Mastery of this technique allows the intensivist to rapidly diagnose and assess respiratory muscle dysfunction in critically ill patients and in patients with unexplained dyspnea. Furthermore, it can be used to assess patient-ventilator interaction and weaning failure in critically ill patients. This paper provides an overview of the basic and advanced principles underlying respiratory muscle ultrasound with an emphasis on the diaphragm. We review different ultrasound techniques useful for monitoring of the respiratory muscle pump and possible therapeutic consequences. Ideally, respiratory muscle ultrasound is used in conjunction with other components of critical care ultrasound to obtain a comprehensive evaluation of the critically ill patient. We propose the ABCDE-ultrasound approach, a systematic ultrasound evaluation of the heart, lungs and respiratory muscle pump, in patients with weaning failure.
\end{abstract}

Keywords: Ultrasonography, Diaphragm ultrasound, Respiratory muscle ultrasound, Diaphragm dysfunction

\section{Introduction}

Ultrasound imaging has become increasingly popular for the diagnosis of deranged physiology and to guide treatment in critically ill patients. In particular, the sonographic evaluation of the heart and lungs is well established and widely implemented in the intensive care unit (ICU) $[1,2]$. The use of ultrasound to evaluate the respiratory muscle pump function is relatively new. The relative infrequency with which respiratory muscle ultrasound is employed in clinical practice may be attributable to the complexity of

\footnotetext{
*Correspondence: I.heunks@amsterdamumc.nl

${ }^{1}$ Department of Intensive Care Medicine, Amsterdam UMC, Location VUmc, Amsterdam, The Netherlands
}

Full author information is available at the end of the article this pump (especially the number of muscles involved), the difficulty in obtaining adequate ultrasound windows, and the common assumption that ultrasound evaluation of the respiratory muscles would not alter patient management in the ICU. The aim of this review is to provide an overview of the principles and current applications of respiratory muscle ultrasound and to discuss its limitations and to describe innovative ultrasound-based techniques. We propose a systematic ultrasound-based evaluation of the respiratory muscle pump, integrated with cardiac and lung ultrasound, in ICU patients.

\section{Anatomy of the respiratory muscles}

The main muscle of inspiration is the diaphragm, a thin dome-shaped muscle positioned between the chest and 
abdomen. Contraction of the zone of apposition (cylindroid part of the diaphragm attached to the thoracic outlet) results in caudal movement of the diaphragm dome, and increases intrathoracic volume. When the load imposed on the diaphragm increases, the accessory inspiratory muscles (parasternal-, external intercostal-, scalene-, and sternocleidomastoid muscles) are recruited. With further loading, the expiratory muscles are activated to assist expiration [3]. The most prominent expiratory muscles include the transversus abdominis muscle and the internal- and external oblique muscles. The differential diagnosis of diaphragm weakness is extensive (Table E1).

\section{Techniques and views \\ Diaphragm}

Two ultrasound approaches to visualize the diaphragm should be performed: the mid-axillary intercostal approach at the zone of apposition, and the subcostal approach using the liver or spleen as an acoustic window. Tips and tricks of respiratory muscle ultrasound are summarized in E-Figure 1.

\section{Intercostal approach: thickness and thickening fraction}

The intercostal approach is performed with a 10-15$\mathrm{MHz}$ linear array transducer positioned in a cranio-caudal direction and perpendicular to the skin in the zone of apposition between the mid-axillary or antero-axillary line, in the 8th to 11th intercostal space (Fig. 1) $[4,5]$. The diaphragm appears at a depth of two to four centimeters as a three-layered structure between the pleural and peritoneal membrane (Fig. 1). Characteristically, a white linear structure is seen in the middle of the diaphragm [4, 5]. We recommend measuring diaphragm thickness perpendicular to its fiber direction between the pleural and peritoneal membrane, but not including the membranes (Fig. 1). The lower limit for normal diaphragm thickness is around $1.5 \mathrm{~mm}$ in healthy subjects. Reference values are given in Table 1. Diaphragm thickness is affected by body composition and gender [6,7].

The diaphragm thickens with active shortening and, therefore, thickening fraction (TF) reflects contractile activity $[8,9]$. Thickening fraction of the diaphragm (TFdi) is calculated in B-mode or M-mode as the percentage inspiratory increase in diaphragm thickness relative to end-expiratory thickness during tidal breathing (TFdi) or maximal inspiratory effort (TFdi(max)): TFdi $=$ (end-inspiratory thickness - end-expiratory thickness)/end-expiratory thickness $\times 100 \%$ (Fig. 1). Inspiratory thickening of the diaphragm can be used to assess muscle function. Reference values are given in Table 1 and demonstrate a relative wide range in healthy subjects $[6,9-11]$. A reasonable relationship exists between
TFdi and the pressure (or electrical activity) developed by the diaphragm during unassisted breathing $[9,12]$ and mechanical ventilation [13]. Few studies directly evaluated the correlation between TFdi and muscle pressure (Pmus) $[14,15]$ and, therefore, care should be taken when estimating Pmus from TFdi.

\section{Subcostal approach: excursion}

Diaphragmatic excursion is measured with a low frequency phased-array or curved-array ("abdominal") probe $(2-5 \mathrm{MHz})$ positioned just below the costal arch at the midclavicular line, with the patient in semi-seated position and by angling the ultrasound beam as much as possible cranially and perpendicular to the diaphragmatic dome (Fig. 1). The diaphragm is identified as a bright line covering the liver and the spleen. Obtaining a clear image of the left hemidiaphragm can be difficult due to the poor acoustic window of the spleen. During inspiration, the diaphragm should move toward the probe (Fig. 1). Excursion is quantified in M-mode, with the M-line placed perpendicular to the direction of motion (Fig. 1); the sweep speed is best adjusted to around $10 \mathrm{~mm} / \mathrm{s}$ to obtain a minimum of three respiratory cycles within one image. Diaphragm excursion should only be measured during unassisted breathing (i.e., T-piece or minimum tolerable CPAP level), since active contraction of the diaphragm cannot be distinguished from passive displacement due to ventilator inspiratory pressures $[4,12]$.

In a cooperative patient, a maximum inspiratory effort is performed to assess maximal excursion. Excursion of both hemidiaphragms is compared to identify unilateral weakness or paralysis (for reference values, see Table 1). The success rate for visualizing excursion is high during tidal breathing (>95\%), whereas during maximal breathing visualization is more difficult, especially on the left side [17].

If experiencing difficulties visualizing the diaphragm from the subcostal window, movement of the liver or spleen during tidal respiration can be used as an alternative. To this end, an intercostal window at the zone of apposition in B- or M-mode is advised, using a low frequency probe $[18,19]$. As there is some inconsistency in agreement between diaphragmatic- and subdiaphragmatic excursion [20,21], it is advised to use this approach for a qualitative rather than a quantitative assessment of diaphragm motion.

Under normal conditions, expiration largely depends on the elastic recoil pressure of the respiratory system, although some diaphragm activity in early expiration has been demonstrated [22]. Nevertheless, diaphragm relaxation rate derived from excursion should not be used as a measure for diaphragm function [16]. 


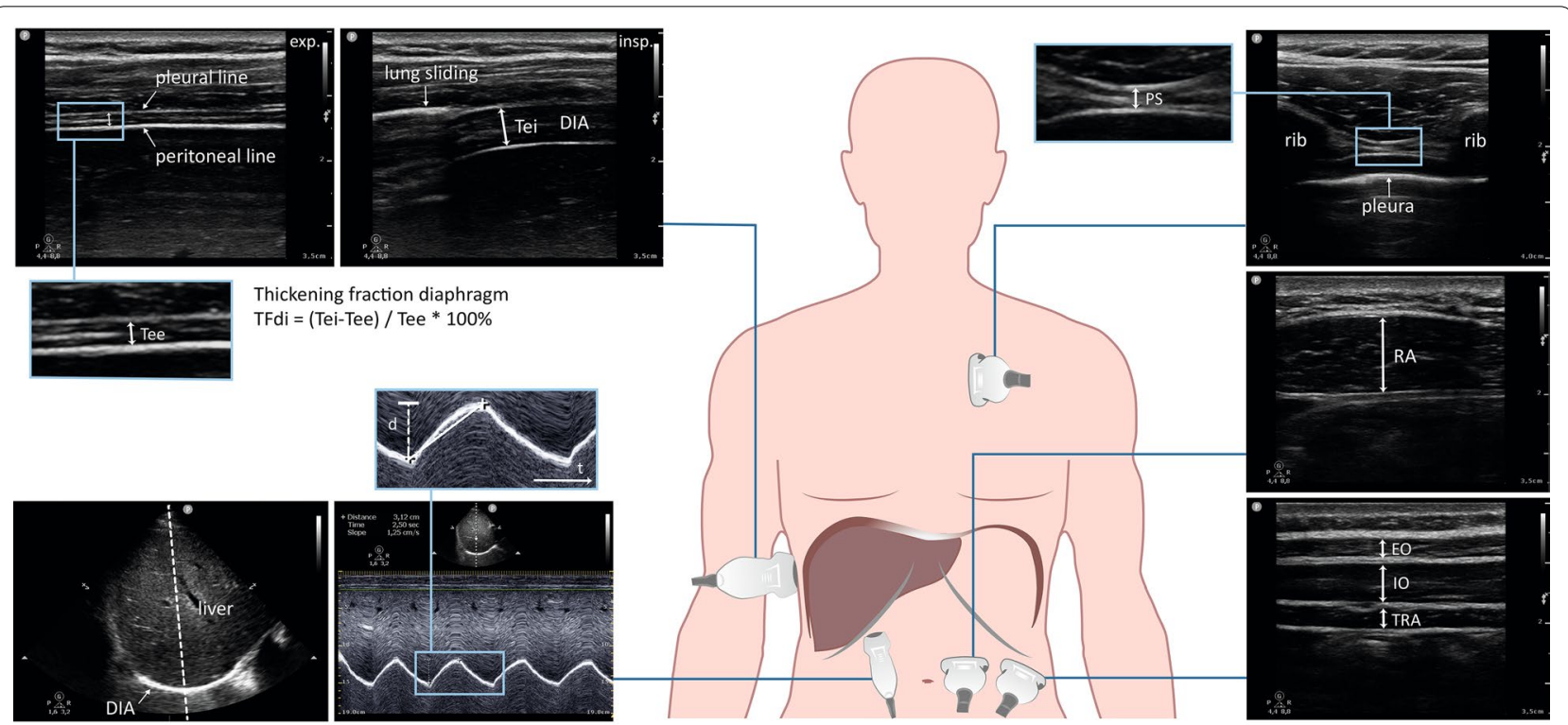

Fig. 1 Clinical application of respiratory muscle ultrasound: techniques and views

\section{Extra-diaphragmatic inspiratory muscles}

Ultrasound assessment of accessory inspiratory muscles could add information regarding patient's inspiratory effort and patient-ventilator interaction. Parasternal intercostal muscle ultrasound is performed with a $10-15 \mathrm{MHz}$ linear probe positioned in cranio-caudal direction at the second intercostal space (Fig. 1). Thickness and inspiratory thickening fraction can be assessed. In healthy subjects, thickening of parasternal intercostal muscles is observed only during maximal efforts [23] and preliminary findings in ICU patients suggest the existence of a dose-response relationship between respiratory load and the parasternal intercostal thickening fraction [24].

Although the topic of future studies, parasternal intercostal muscle ultrasound may be a useful tool in the evaluation of the capacity/load balance of the respiratory muscle pump in the ventilated patient. Reference values need to be determined.

\section{Abdominal wall expiratory muscles}

Using a 10-15 MHz linear probe positioned perpendicular to the abdominal wall, with the patient in supine position, the different expiratory muscles are relatively easily to visualize as hypoechogenic layers enclosed by fascial sheaths (Fig. 1). The pressure applied to the probe should be kept to a minimum to prevent compression of the abdominal wall as this may alter the shape/thickness of the underlying muscles.
To visualize the rectus abdominis muscle, the transducer is positioned in a transverse orientation approximately $2-3 \mathrm{~cm}$ above the umbilicus and $2-3 \mathrm{~cm}$ lateral from the midline (Fig. 1) [25]. Maximum muscle thickness is obtained by sliding the probe in a cranial-caudal direction, while keeping the probe perpendicular to the skin. Next, the probe is moved laterally; the semilunar line is first identified as a thick echogenic fascia that blends lateral to the rectus abdominis muscle and medial to the oblique muscles. The external oblique, internal oblique and transversus abdominis muscles can be identified as three parallel layers (Fig. 1), usually best visualized on the anterior axillary line, midway between the inferior border of the rib cage and the iliac crest [25-27]. Reference values are provided in E-Table 2 [25-28].

Thickening fraction of the expiratory abdominal muscles (TFabd) can be calculated as the magnitude of thickness increase during expiration $(\mathrm{TFadb}=$ (end-expiratory thickness - end-inspiratory thickness)/end-inspiratory thickness) $\times 100 \%$ ) and may reflect expiratory muscle effort. Preliminary data seem to demonstrate reasonable correlation between TFabd and expiratory force generation [29]. It should be noted that expiratory muscles have more degrees of freedom compared to the diaphragm; active contraction of one muscle layer may directly affect the shortening and position of the adjacent layer, which may make interpretation of TFabd more complex. Moreover, the relationship between shortening, thickening, and pressure generation is complex because of the geometry of the abdominal muscles during contraction (a 
Table 1 Reference values for diaphragm muscle ultrasound in ICU patients and in the general population

\begin{tabular}{|c|c|c|c|c|c|}
\hline Setting & Parameter & Patient position & Reference values & $\begin{array}{l}\text { Abnormal values/values } \\
\text { related to outcome }\end{array}$ & References \\
\hline \multirow[t]{12}{*}{ ICU } & Thickness (mm) & - & $2.4 \pm 0.8$ & & [9] \\
\hline & & Semi-recum & $2.4(2.0-2.9)$ & & [75] \\
\hline & & Semi-recum & & $<1.7$ & [60] \\
\hline & & Semi-recum & $1.9 \pm 0.4$ & & {$[76]$} \\
\hline & TFdi & Semi-recum & & $<30 \%$ & [60] \\
\hline & TFdi(max) & Semi-recum & & $<36 \%$ & [59] \\
\hline & TFdi & Semi-recum & & $<34 \%$ & [52] \\
\hline & Tidal excursion (mm) & Supine & & $<11$ (organ exc.) & {$[77]$} \\
\hline & & Semi-recum & & Right $<14$ & [51] \\
\hline & Maximal breath (mm) & Semi-recum & & Left $<12$ & [52] \\
\hline & & Semi-recum & & $<10$ & [53] \\
\hline & & & & $<25$ & \\
\hline \multirow[t]{14}{*}{ General population } & Thickness (mm) & Sitting & $1.7 \pm 0.2$ & & [78] \\
\hline & & Standing & $2.8 \pm 0.4$ & $<1.9$ & [10] \\
\hline & & Supine & $3.3 \pm 1.0$ & $<1.4$ & [6] \\
\hline & & Supine & $1.6 \pm 0.4$ & $<1.5$ & [7] \\
\hline & & & Men: $1.9 \pm 0.4$ & $<1.7$ & \\
\hline & & & Women: $1.4 \pm 0.3$ & $<1.3$ & \\
\hline & TFdi(max) & Standing & $37 \pm 9 \%$ & $<20 \%$ & [10] \\
\hline & & Supine & $80 \pm 50 \%$ & $<20 \%$ & [6] \\
\hline & Tidal excursion (mm) & Standing & Men: $18 \pm 3$ & Men: $<10$ & [17] \\
\hline & & & Women: $16 \pm 3$ & Women: $<9$ & \\
\hline & Sniff test (mm) & Standing & Men: $29 \pm 6$ & Men: $<18$ & \\
\hline & & & Women: $26 \pm 5$ & Women: $<16$ & \\
\hline & Maximal breath (mm) & Standing & Men: $70 \pm 11$ & Men: $<47$ & \\
\hline & & & Women: $57 \pm 10$ & Women: $<37$ & \\
\hline
\end{tabular}

Thickness and excursion values are expressed in millimeter. Normal values are expressed as mean \pm SD or median (range); for ICU patients, mean thickness values are reported from baseline measurements. TFdi: thickening fraction tidal breathing (or during maximal breathing $=$ TFdi(max)), expressed in \%; Position is presented as described in the original manuscript, although sitting and semi-recumbent (and potentially supine) may have overlap. Semi-recum $=$ semi-recumbent; $-=$ not mentioned in the manuscript

'shrinking' sphere rather than a 'shortening piston-in-acylinder' like the diaphragm). Future studies should confirm the relationship between expiratory muscle pressure and TFabd and its clinical relevance.

\section{Clinical applications of respiratory muscle ultrasound (Table 2)}

Role of respiratory muscle ultrasound in acute respiratory failure

Respiratory muscle weakness as the major cause for acute respiratory failure is uncommon, but should be considered if more common causes have been excluded [30, 31]. The clinical presentation of diaphragm dysfunction depends on the cause, severity and rate of progression (E-Table 1) [32]. A characteristic physical sign of bilateral diaphragm dysfunction is supine abdominal paradox: activity of accessory inspiratory muscles generates a negative inspiratory thoracic pressure (though the same pattern may be observed when respiratory loads are increased) [33]. As the diaphragm is paralyzed, this negative pressure is transferred to the abdomen, resulting in inward movement of the abdominal wall. The ultrasound corollary of this is cranial excursion of the diaphragm during inspiration, measured in M-mode. In addition, severe isolated diaphragm weakness results in an increased thickening fraction of the accessory respiratory muscles [24]. Therefore, respiratory muscle ultrasound is an excellent modality to diagnose (unilateral) diaphragm weakness or paralysis in patients with acute respiratory failure [34, 35].

Diaphragm weakness is diagnosed by an excursion of $<10-15 \mathrm{~mm}$ during tidal breathing or a TFdi $(\max )<20 \%$ (Table 1$)[6,7,10]$. In patients with unilateral diaphragm paralysis, thickness and TFdi of the paralyzed diaphragm were significantly less compared to the other hemidiaphragm (Table 1) [10]. A left-right ratio for 
thickness of $<0.5$ or $>1.6$ should be considered abnormal [19]. Notably, with unilateral diaphragmatic dysfunction the normal hemidiaphragm may show relatively large excursions, a compensatory mechanism to generate sufficient tidal volumes [36, 37]. For patients with bilateral paralysis, diaphragm thickness and TFdi are below reference values [10].

In patients with acute hypercapnic exacerbation of COPD (AE-COPD), diaphragm ultrasound may be used to predict success of non-invasive ventilation (NIV). Increased diaphragm excursion during NIV $(>18 \mathrm{~mm}$ vs $<12 \mathrm{~mm}$ ) was associated with NIV success and a decrease in $\mathrm{Paco}_{2}$ after one hour [38, 39]. Air trapping has been found to be the major limiting factor in diaphragm excursion in COPD patients [40]; therefore, improved excursion is probably an indication of reduced pulmonary hyperinflation. In a cohort of patients with AE-COPD requiring ICU admission $(n=41)$, TFdi $<20 \%$ was associated with NIV-failure $(R=0.51)$ [41], which was confirmed in a larger $(n=75)$ follow-up study (risk ratio for NIV-failure 4.4) [42]. Diaphragm ultrasound may thus reduce the risk of delayed intubation in patients with severe AE-COPD requiring NIV; however, further validation is required.

\section{Role of respiratory muscle ultrasound in diaphragm-protective mechanical ventilation}

It has been postulated that both ventilator over-assist and ventilator under-assist, resulting in muscle atrophy and muscle injury, respectively, play an important role in critical illness-associated diaphragm weakness pathophysiology [13]. To limit these detrimental consequences, it seems reasonable to titrate ventilator support such that diaphragm effort is within physiological limits, the so-called diaphragm protective mechanical ventilation [13, 43, 44]. The optimal level of diaphragm activity is currently unknown and may vary under different conditions (e.g., sepsis, weakness); however, a relatively low level of diaphragm activity, corresponding to esophageal pressure swings of 4-8 $\mathrm{cm} \mathrm{H}_{2} \mathrm{O}$ appears safe [45]. The role of ultrasound in diaphragm protective ventilation has not been specifically studied, but assessment of

Table 2 Clinical indications and role of ultrasound of the respiratory muscles in adults admitted in the intensive care unit or emergency department

\begin{tabular}{|c|c|c|c|c|}
\hline Setting & Indication & $\begin{array}{l}\text { Role of respiratory muscle } \\
\text { ultrasound }\end{array}$ & Diagnostic performance & Limitations \\
\hline \multirow[t]{5}{*}{ ICU } & Difficult weaning & Excursion and TFdi detect DD & $\begin{array}{l}\text { Excursion poor to moderate } \\
\text { TFdi moderate } \\
\text { Better during SBT } \\
\text { Combined with clinical param- } \\
\text { eters better performance }\end{array}$ & $\begin{array}{l}\text { A significant portion of patients } \\
\text { diagnosed with DD can be } \\
\text { successfully extubated }\end{array}$ \\
\hline & Titrate ventilator support & $\begin{array}{l}\text { Detection of underuse/overuse } \\
\text { using TFdi }\end{array}$ & & Needs further validation \\
\hline & Patient-ventilator interaction & $\begin{array}{l}\text { Excursion and/or TFdi (com- } \\
\text { pared to ventilator waveforms) } \\
\text { can detect different types of } \\
\text { asynchrony }\end{array}$ & Good/easy repeatable & $\begin{array}{l}\text { Variability of the effectiveness } \\
\text { between subjects } \\
\text { Not suitable for continuous } \\
\text { monitoring }\end{array}$ \\
\hline & Estimating work of breathing & TFdi & $\begin{array}{l}\text { Large range of effort at certain } \\
\text { TFdi }\end{array}$ & Needs further validation \\
\hline & $\begin{array}{l}\text { Clinical suspicion of iatrogenic n. } \\
\text { phrenicus lesion (e.g., postop- } \\
\text { erative) }\end{array}$ & $\begin{array}{l}\text { Excursion can detect (unilateral) } \\
\text { paralysis/weakness }\end{array}$ & Good & None \\
\hline \multirow[t]{2}{*}{ ED } & Dyspnea of unknown origin & $\begin{array}{l}\text { Excursion/TFdi can detect weak- } \\
\text { ness/paralysis }\end{array}$ & High sens and spec & None \\
\hline & AECOPD & Excursion/TFdi predict NIV-failure & Moderate & Needs further validation \\
\hline \multirow[t]{4}{*}{ Both } & $\begin{array}{l}\text { Unilateral diaphragm relaxation } \\
\text { on chest X-ray }\end{array}$ & Excursion/TFdi/left to right ratio & Good & None \\
\hline & $\begin{array}{l}\text { Diagnosing and monitoring } \\
\text { of diaphragmatic weakness/ } \\
\text { paralysis }\end{array}$ & & Good, no technical failures & \\
\hline & $\begin{array}{l}\text { Stroke with respiratory impair- } \\
\text { ment }\end{array}$ & & $\begin{array}{l}\text { Good detection of diaphragm } \\
\text { involvement }\end{array}$ & None \\
\hline & $\begin{array}{l}\text { Neuromuscular disorders } \\
\text { Cervical spine lesions }\end{array}$ & & $\begin{array}{l}\text { May help predict need for } \\
\text { mechanical ventilation }\end{array}$ & \\
\hline
\end{tabular}

$A E C O P D$ acute exacerbation of chronic obstructive pulmonary disease, $D D$ diaphragm dysfunction, $E D$ emergency department, $I C U$ intensive care unit, NIV noninvasive ventilation, SBT spontaneous breathing trial, TFdi diaphragm thickening fraction 
TFdi, as a proxy for effort, is a reasonable approach. Data from Goligher and colleagues demonstrate that a TFdi between 15 and 30\% during the first days of mechanical ventilation is associated with stable muscle thickness [44] and the shortest duration of ventilation [13]. Accordingly, a low TFdi $(<15 \%)$ in a patient on a partially supported ventilatory mode raises the possibility of ventilator overassist; therefore, decreasing assist, while monitoring other respiratory parameters (e.g., tidal volume, respiratory rate), is a reasonable approach. The upper limit for TFdi allowing diaphragm protective ventilation is more controversial. Although a moderate and statistically significant correlation exists between TFdi and diaphragm effort (Pdi, PTP) [9, 14], the range of diaphragm effort at a certain TFdi is large. We suggest that in patients with TFdi $>30-50 \%$, ventilator support may be increased under the monitoring of other respiratory parameters to avoid hyperinflation. Given the relative imprecision of TFdi measurements, other techniques for monitoring respiratory effort should be considered.

\section{Role of respiratory muscle ultrasound in weaning failure}

An imbalance between load and capacity of the respiratory system is an important cause for SBT failure and extubation failure [46]. Therefore, respiratory muscle ultrasound could play an important role in the differential diagnosis of weaning failure. However, it is important to emphasize that a substantial proportion of patients can be successfully weaned from the ventilator despite having diaphragm dysfunction [47-49]. In addition, the clinical relevance of predicting SBT outcome with ultrasound is debatable; more relevant from a clinical perspective is the use of ultrasound to predict extubation success.

\section{Diaphragm excursion}

Kim et al. evaluated diaphragm excursion in a series of 89 patients on a T-tube, before the start of an SBT [50]. Diaphragm dysfunction-arbitrary defined as excursion $<10 \mathrm{~mm}$ was associated with weaning failure, but its predictive performance was poor (AUROC 0.61). Using the same cutoff, no association was found between diaphragm dysfunction and extubation failure [51]. Interestingly, when diaphragm excursion is measured after $30 \mathrm{~min}$ from initiation of a $2 \mathrm{~h} \mathrm{SBT}$, predictive performance of $10 \mathrm{~mm}$ cutoff seems to be significantly higher (AUROC 0.88) [52]. Post-cardiac surgery patients with unilateral diaphragmatic paralysis could be extubated without delay, when the contralateral diaphragm excursion was $>25 \mathrm{~mm}$ at maximal inspiratory effort [53]. In a meta-analysis of 10 studies evaluating diaphragm excursion to predict weaning failure and combining different definitions of weaning failure, the authors reported a sensitivity of $75 \%$ (95\% CI 65-85) and specificity of $75 \%$
(95\% CI 60-85), with substantial heterogeneity [54]. As diaphragm excursion is strongly dependent of lung volume [37], the reported heterogeneity could be explained by patient position and the timing of measurements, e.g., before/during the SBT and with or without ventilator assistance.

Spadaro et al. [55] evaluated the diaphragmatic-rapid shallow breathing index (D-RSBI: respiratory rate divided by diaphragm excursion) during a T-tube SBT and reported good performance as compared to RSBI alone (D-RSBI AUROC 0.89 vs RSBI AUROC 0.72, respectively, $P=0.006$ ). Palkar et al. [56] evaluated the performance of the diaphragmatic excursion-time product (i.e., $\mathrm{E}-\mathrm{T}$ index), the product of diaphragm excursion $(\mathrm{cm})$ and inspiratory time $(\mathrm{s})$. A decrease in $\mathrm{E}-\mathrm{T}$ index of $<3.8 \%$ between assisted control ventilation and a PSV $\left(5 / 5 \mathrm{H}_{2} \mathrm{O}\right)$ SBT had a sensitivity of $79.2 \%$ and a specificity of $75 \%$ to predict extubation success.

Remarkably, in 191 patients having successfully passed an SBT, diaphragm excursion was not associated with extubation failure [57]. This suggests that once an SBT is successfully completed, extubation outcome is primarily determined by factors other than diaphragm function.

\section{Diaphragm thickening fraction}

When performed during an SBT, TFdi $>30-36 \%$ has shown to predict extubation success [52, 54, 58]. Ferrari et al. evaluated in 46 patients ventilated through a tracheostomy tube, the role of TFdi(max) of the right hemidiaphragm during an SBT, as a predictor of weaning outcome [59] and reported that a TFdi $(\max )>36 \%$ was associated with a successful SBT (sensitivity 0.82; specificity 0.88; AUROC 0.95). In another study, TFdi was calculated either during T-tube or low levels of pressure support ventilation in patients $(N=63)$ after a failed weaning attempt. A TFdi $\geq 30 \%$ had a sensitivity of 0.88 and specificity of 0.71 (AUROC 0.79 ) for extubation success [60]. In the above-mentioned meta-analysis assessing the predictive value of diaphragm excursions, TFdi/ TFdi (max) demonstrated an AUROC of 0.87 and diagnostic odds ratio of 21 (95\% CI 11-40) for prediction of weaning failure [54]. The diagnostic odds ratio is a measure of effectiveness of a diagnostic test and it is defined as the ratio of odds of a test being positive if the subject has the disease relative to the odds of the test being positive if the subject does not have the disease.

Overall, these results seem to suggest a role for diaphragm ultrasound in the differential diagnosis of patients experiencing difficult weaning, allowing bedside recognition of diaphragmatic weakness. However, the role of diaphragm ultrasound to predict successful SBT 
and successful extubation requires further evaluation and currently cannot be recommended.

\section{The $A B C D E$ approach: a systematic ultrasound evaluation of patients with weaning failure}

A weaning trial may be considered as a cardio-pulmonary stress test: it demands an increase in cardiac index, oxygen demand/consumption, and breathing effort. In most patients, post-extubation distress is the result of a combination of cardiac dysfunction, impaired gas exchange, and/or diaphragmatic dysfunction. Therefore, in patients with weaning failure we suggest the use of a structured and integrated approach that combines clinical parameters, laboratory parameters (e.g., pro-BNP) and the sonographic assessment of the lung, heart and the respiratory muscles [61]. Here, we present the ABCDE-Ultrasound approach, an intuitive aid designed to standardize the sonographic approach to weaning failure (Fig. 2). A similar but less exhaustive approach has been suggested by Mayo et al. [62]. The use of ultrasound to evaluate the heart and lung has been described in this Intensive Care Medicine critical care ultrasound series [1,2]. Timing of ultrasound examination depends on the clinical question. For identification of patients at high-risk of weaning failure, the examination is performed before the SBT. For prediction of weaning outcome or to diagnose the cause of weaning failure, the examination is best done after the start and/or end of an SBT [62].

\section{Role of respiratory muscle ultrasound to assess patient- ventilator interaction}

Patient-ventilator asynchrony can be defined as a mismatch between the neural inspiratory time and ventilator inspiratory time [63]. Patient-ventilator asynchrony is associated with worse outcome [64] and occurs in up to half of mechanically ventilated patients. Visual inspection of the airway flow and pressure signal may detect asynchrony, but was shown to be unreliable [65]. Both measurements of esophageal pressure and diaphragm electrical activity are used as state-of-the-art techniques to assess patient-ventilator interactions [66]. These two techniques are invasive, limiting their use in daily practice. Diaphragm ultrasound might be a reasonable alternative to detect most types of patient-ventilator asynchrony (Table 3 ), but further studies are needed to determine its exact role $[4,67]$.

\section{Limitations of respiratory muscle ultrasound}

We briefly summarize current challenges of respiratory muscle ultrasound. This highlights the need for a systematic ultrasound approach to be implemented in clinical practice and research.

\section{Reproducibility}

The first and largest study regarding reliability of diaphragm thickness and TFdi measurements in mechanically ventilated patients $(n=66)$ was conducted by Goligher et al. [68]. Measurements were performed after marking the probe location. Intra-observer and interobserver reproducibility coefficients for end-expiratory diaphragm thickness were $0.2 \mathrm{~mm}$ and $0.4 \mathrm{~mm}$, respectively [68], meaning it is expected that the absolute difference between two measurements by the same observer does not differ by more than $0.2 \mathrm{~mm}$ on $95 \%$ of occasions (or $0.4 \mathrm{~mm}$ in case of two different observers). However, it should be kept in mind that $0.2 \mathrm{~mm}$ represents approximately $10 \%$ of total diaphragm thickness at end expiration. While in general diaphragm ultrasound seems to be a reliable technique to assess changes in diaphragm thickness over time, comparing individual patient results should be done with a degree of caution and only after adequate training, as small observer-dependent variations (e.g., measurement location, probe angulation) will affect results.

\section{Accuracy}

Accurate muscle thickness measurement depends not only on operator skills but also on technical aspects related to ultrasound physics and patient characteristics. Unclarity of surrounding membranes and insufficient ultrasound beam angulation to muscle axis may lead to measurement error. Furthermore, the spatial axial resolution (depth resolution, i.e., $1 / 2$ spatial pulse length) of the probe plays a critical role. Given that the ultrasound pulse length is typically two cycles and that the ultrasound wavelength of a $10 \mathrm{MHz}$ transducer is $0.15 \mathrm{~mm}$ (i.e., wavelength $=$ speed of sound in soft tissue/frequency $=1540 \mathrm{~m} / \mathrm{s} / 10 \mathrm{MHz}=0.15 \mathrm{~mm}$ ), the corresponding depth resolution is $1 / 2(2 \times 0.15)=0.15 \mathrm{~mm}$, which is in the same order as the intra-observer reproducibility and sufficient in order to visualize the diaphragm. Based on the ultrasound technique and equipment used, identification of the smallest detectable change that is permitted is fundamental to distinguish true changes in muscle thickness from artifact.

\section{Research: novel techniques and future developments for functional imaging and quantification of tissue properties Tissue Doppler imaging}

Tissue Doppler imaging (TDI) quantifies the velocity of moving structures [69]. This could be an interesting modality superimposed over the B-mode diaphragm excursion images for quantification of diaphragm kinetics (video online supplement). Feasibility and reliability of diaphragm TDI have been confirmed in neonates [70] and the role of TDI for assessment of diaphragm mobility 


\section{PoCUS in WEANING FAILURE}

ABCDE-ultrasound approach

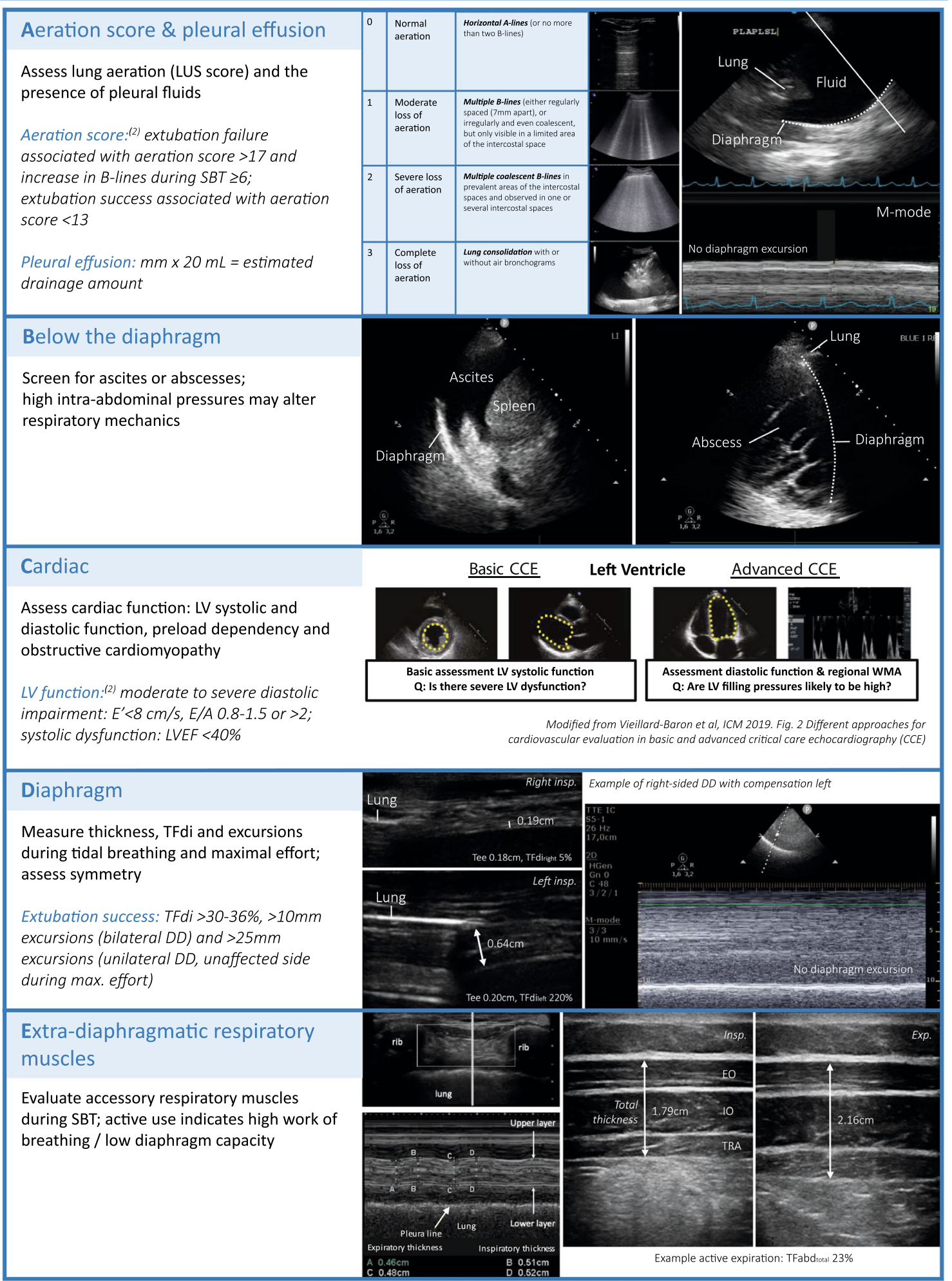

Fig. 2 Point-of-Care Ultrasound (PoCUS) in patients with weaning failure: the ABCDE approach 
Table 3 Types of patient-ventilator asynchronies and their ultrasound correlate

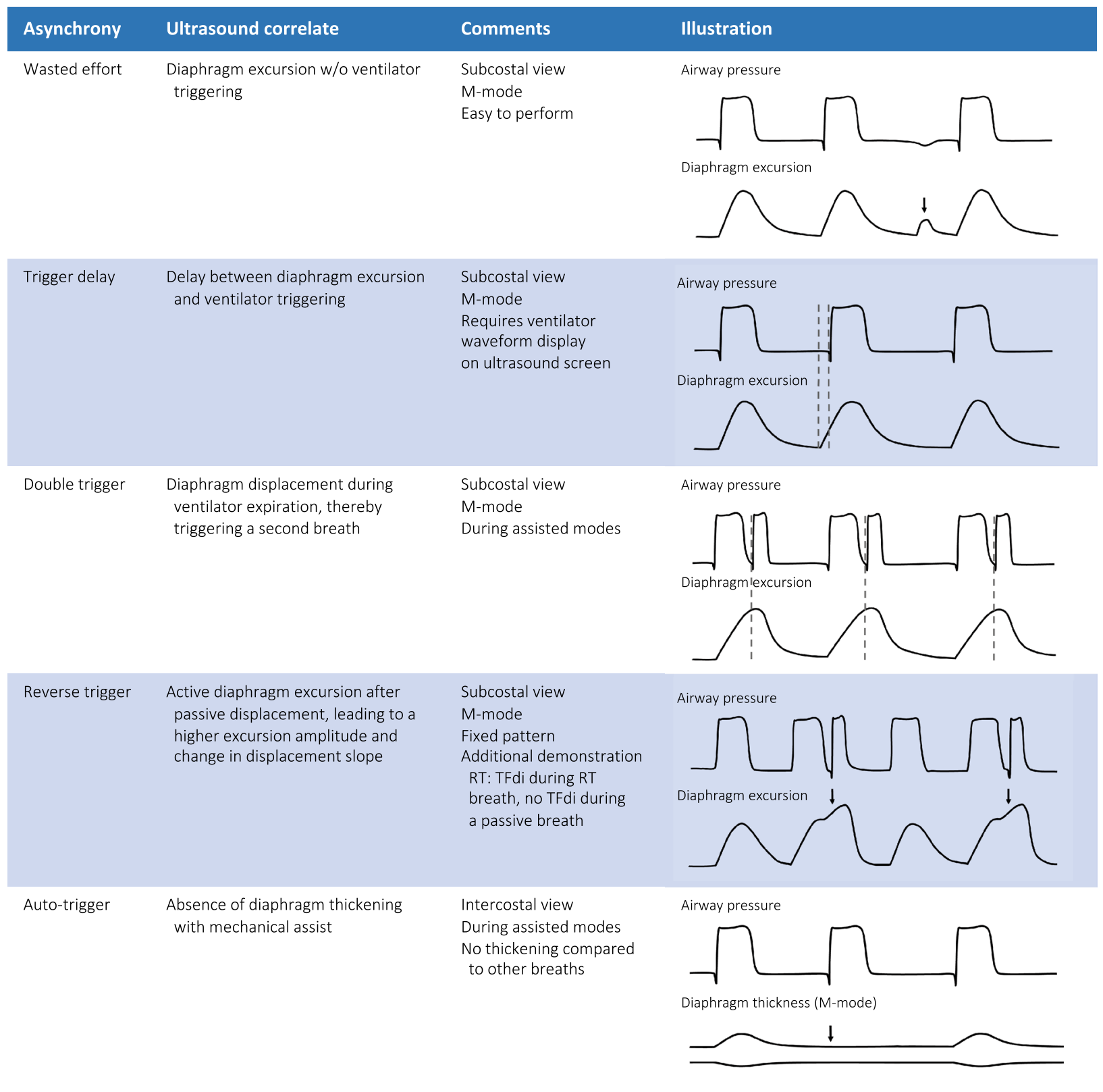

$R T$ reverse trigger, TFdi diaphragm thickening fraction

and dysfunction in patients following cardiac surgery is under investigation (ClinicalTrials.gov; NCT03295344). Potential applications include assessment of regional diaphragm contractile function at rest and with loading, and measurement of diaphragm relaxation velocity. Diaphragm relaxation abnormalities have been described as a marker of impaired contractility in patients who failed weaning [71], but nowadays they can only be assessed with invasive esophageal or diaphragmatic pressure measurements (or possibly M-mode excursion decay).

\section{Strain imaging}

Strain imaging is based on the ability to track ultrasound speckles over time and an excellent feature to quantify motion and deformation of anatomical structures. This 
has a great benefit over TDI, as strain imaging is not affected by the angle between the ultrasound beam and the direction of tissue motion. Furthermore, it allows calculation of displacement, velocity, and deformation of tissue in two directions. It was recently demonstrated that strain and strain rate were highly correlated to transdiaphragmatic pressure in healthy subjects [72]. In addition, Goutman and colleagues applied speckle tracking for evaluating true diaphragm excursion in two directions, which is more accurate compared to measurements of motion along one M-mode line [73].

\section{Shear wave elastography}

Shear wave elastography is a technique that allows quantification of the elastic modulus of tissues (E-Figure. 2). Application of this technique on the diaphragm could be of clinical importance since changes in muscle stiffness may reflect alterations in muscle physiology (e.g., injury, fibrosis). Moreover, shear wave elastography is considered to be more accurate and reproducible than evaluation of echogenicity, which is highly dependent on ultrasound settings (e.g., gain, contrast, etc.). A recently published proofof-concept work demonstrated that changes in diaphragm stiffness during inspiratory efforts as assessed with ultrasound shear wave elastography reflect changes in transdiaphragmatic pressure [74]. Therefore, it might offer a new non-invasive method for gauging diaphragm effort.

\section{Conclusion}

Respiratory muscle ultrasound is a widely available, highly feasible, non-invasive bedside radiation-free technique that can be easily applied at the bedside. It is, therefore, the imaging modality of choice for assessment of the respiratory muscles in ICU patients. Mastery of respiratory muscle ultrasound allows the intensivist to rapidly obtain information on global function of the respiratory muscle pump, in particular to diagnose diaphragm weakness or paralysis. In combination with cardiac and lung ultrasound, it can detect patients at risk for difficult weaning, predict weaning outcome and help diagnose the cause of weaning failure. A structured ultrasound approach for these patients is presented.

\section{Electronic supplementary material}

The online version of this article (https://doi.org/10.1007/s00134-019-05892-8) contains supplementary material, which is available to authorized users.

\footnotetext{
Author details

1 Department of Intensive Care Medicine, Amsterdam UMC, Location VUmc, Amsterdam, The Netherlands. ${ }^{2}$ Amsterdam Leiden Intensive Care Focused Echography (ALIFE), Amsterdam, The Netherlands. ${ }^{3}$ Department of Pulmology and Medical Intensive Care, APHP Sorbonne Université, Pitié-Salpêtrière Hospital, Paris, France. ${ }^{4}$ Department of Critical Care Medicine, Capital Medical University, Beijing Tiantan Hospital, Beijing 100050, China. ${ }^{5}$ Interdepartmental Division of Critical Care Medicine and Department of Medicine, University of Toronto, Toronto, ON, Canada. ${ }^{6}$ Critical Care Medicine, University Health
}

Network, Toronto General Hospital, Toronto, ON, Canada. ${ }^{7}$ Division of Critical Care Medicine, Department of Medicine, St. Michael's Hospital, Toronto, ON, Canada. ${ }^{8}$ Department of Radiology, Radboud UMC, Nijmegen, The Netherlands.

\section{Compliance with Ethical Statement}

\section{Conflict of interest}

None of the authors has any conflict to declare.

\section{Open Access}

This article is licensed under a Creative Commons Attribution-NonCommercial 4.0 International License, which permits any non-commercial use, sharing, adaptation, distribution and reproduction in any medium or format, as long as you give appropriate credit to the original author(s) and the source, provide a link to the Creative Commons licence, and indicate if changes were made. The images or other third party material in this article are included in the article's Creative Commons licence, unless indicated otherwise in a credit line to the material. If material is not included in the article's Creative Commons licence and your intended use is not permitted by statutory regulation or exceeds the permitted use, you will need to obtain permission directly from the copyright holder.To view a copy of this licence, visit http://creativecommons.org/licen ses/by-nc/4.0/.

\section{Publisher's Note}

Springer Nature remains neutral with regard to jurisdictional claims in published maps and institutional affiliations.

Received: 4 November 2019 Accepted: 2 December 2019 Published online: 14 January 2020

\section{References}

1. Vieillard-Baron A, Millington SJ, Sanfilippo F, Chew M, Diaz-Gomez J, McLean A, Pinsky MR, Pulido J, Mayo P, Fletcher N (2019) A decade of progress in critical care echocardiography: a narrative review. Intensive Care Med 45:770-788

2. Mayo PH, Copetti R, Feller-Kopman D, Mathis G, Maury E, Mongodi S, Mojoli F, Volpicelli G, Zanobetti M (2019) Thoracic ultrasonography: a narrative review. Intensive Care Med 45:1200-1211

3. Shi ZH, Jonkman A, de Vries H, Jansen D, Ottenheijm C, Girbes A, Spoelstra-de Man A, Zhou JX, Brochard L, Heunks L (2019) Expiratory muscle dysfunction in critically ill patients: towards improved understanding. Intensive Care Med 45:1061-1071

4. Matamis D, Soilemezi E, Tsagourias M, Akoumianaki E, Dimassi S, Boroli F, Richard JC, Brochard L (2013) Sonographic evaluation of the diaphragm in critically ill patients. Technique and clinical applications. Intensive Care Med 39:801-810

5. Haaksma ME, Atmowihardjo L, Heunks L, Spoelstra-de Man A, Tuinman PR (2018) Ultrasound imaging of the diaphragm: facts and future. A guide for the bedside clinician. Neth J Crit Care 26:58-63

6. Boon AJ, Harper CJ, Ghahfarokhi LS, Strommen JA, Watson JC, Sorenson EJ (2013) Two-dimensional ultrasound imaging of the diaphragm: quantitative values in normal subjects. Muscle Nerve 47:884-889

7. Carrillo-Esper R, Perez-Calatayud AA, Arch-Tirado E, Diaz-Carrillo MA, Garrido-Aguirre E, Tapia-Velazco R, Pena-Perez CA, Espinoza-de Los Monteros I, Meza-Marquez JM, Flores-Rivera OI, Zepeda-Mendoza AD, de la Torre-Leon T (2016) Standardization of sonographic diaphragm thickness evaluations in healthy volunteers. Respir Care 61:920-924

8. Wait JL, Nahormek PA, Yost WT, Rochester DP (1989) Diaphragmatic thickness lung volume relationship invivo. J Appl Physiol 67:1560-1568

9. Goligher EC, Laghi F, Detsky ME, Farias P, Murray A, Brace D, Brochard LJ, Bolz SS, Rubenfeld GD, Kavanagh BP, Ferguson ND (2015) Measuring diaphragm thickness with ultrasound in mechanically ventilated patients: feasibility, reproducibility and validity (vol 41, pg 642, 2015). Intens Care Med 41:734

10. Gottesman E, McCool FD (1997) Ultrasound evaluation of the paralyzed diaphragm. Am J Respir Crit Care Med 155:1570-1574 
11. Cohn D, Benditt JO, Eveloff S, McCool FD (1997) Diaphragm thickening during inspiration. J Appl Physiol 83:291-296

12. Dube BP, Dres M, Mayaux J, Demiri S, Similowski T, Demoule A (2017) Ultrasound evaluation of diaphragm function in mechanically ventilated patients: comparison to phrenic stimulation and prognostic implications. Thorax 72:811-818

13. Goligher EC, Dres M, Fan E, Rubenfeld GD, Scales DC, Herridge MS, Vorona S, Sklar MC, Rittayamai N, Lanys A, Murray A, Brace D, Urrea C, Reid WD, Tomlinson G, Slutsky AS, Kavanagh BP, Brochard LJ, Ferguson ND (2018) Mechanical ventilation-induced diaphragm atrophy strongly impacts clinical outcomes. Am J Respir Crit Care Med 197:204-213

14. Vivier E, Mekontso Dessap A, Dimassi S, Vargas F, Lyazidi A, Thille AW Brochard L (2012) Diaphragm ultrasonography to estimate the work of breathing during non-invasive ventilation. Intensive Care Med 38:796-803

15. Umbrello M, Formenti P, Longhi D, Galimberti A, Piva I, Pezzi A, Mistraletti G, Marini JJ, lapichino G (2015) Diaphragm ultrasound as indicator of respiratory effort in critically ill patients undergoing assisted mechanical ventilation: a pilot clinical study. Crit Care 19:161

16. Coirault C, Chemla D, Lecarpentier Y (1999) Relaxation of diaphragm muscle. J Appl Physiol 87(1985):1243-1252

17. Boussuges A, Gole Y, Blanc P (2009) Diaphragmatic motion studied by m-mode ultrasonography: methods, reproducibility, and normal values. Chest 135:391-400

18. Haji K, Royse A, Green C, Botha J, Canty D, Royse C (2016) Interpreting diaphragmatic movement with bedside imaging, review article. J Crit Care 34:56-65

19. Houston JG, Morris AD, Howie CA, Reid JL, Mcmillan N (1992) Technical report — quantitative assessment of diaphragmatic movement-a reproducible method using ultrasound. Clin Radiol 46:405-407

20. Haji K, Royse A, Tharmaraj D, Haji D, Botha J, Royse C (2015) Diaphragmatic regional displacement assessed by ultrasound and correlated to subphrenic organ movement in the critically ill patients-an observational study. J Crit Care 30(439):e413-e437

21. Toledo NS, Kodaira SK, Massarollo PC, Pereira OI, Dalmas JC, Cerri GG, Buchpiguel CA (2006) Left hemidiaphragmatic mobility: assessment with ultrasonographic measurement of the craniocaudal displacement of the splenic hilum and the inferior pole of the spleen. J Ultrasound Med 25:41-49

22. Doorduin J, Roesthuis LH, Jansen $\mathrm{D}$, van der Hoeven JG, van Hees HWH, Heunks LMA (2018) Respiratory muscle effort during expiration in successful and failed weaning from mechanical ventilation. Anesthesiology 129:490-501

23. Yoshida R, Tomita K, Kawamura K, Nozaki T, Setaka Y, Monma M, Ohse $H$ (2019) Measurement of intercostal muscle thickness with ultrasound imaging during maximal breathing. J Phys Ther Sci 31:340-343

24. Dres M, Dupe B-P, Goligher EC et al. (2018) Intercostal muscle ultrasound activity: a feasibility and physiological study in mechanically ventilated patients. ATS: A5863

25. Tahan N, Khademi-Kalantari K, Mohseni-Bandpei MA, Mikaili S, Baghban AA, Jaberzadeh S (2016) Measurement of superficial and deep abdominal muscle thickness: an ultrasonography study. J Physiol Anthropol 35:17

26. Misuri G, Colagrande S, Gorini M, landelli I, Mancini M, Duranti R, Scano G (1997) In vivo ultrasound assessment of respiratory function of abdominal muscles in normal subjects. Eur Respir J 10:2861-2867

27. Rankin G, Stokes M, Newham DJ (2006) Abdominal muscle size and symmetry in normal subjects. Muscle Nerve 34:320-326

28. Springer BA, Mielcarek BJ, Nesfield TK, Teyhen DS (2006) Relationships among lateral abdominal muscles, gender, body mass index, and hand dominance. J Orthop Sports Phys Ther 36:289-297

29. Schreiber ASU, Vorona S, Bertoni M, Piva S, Goligher E (2019) Measuring abdominal muscle function by abdominal muscle thickening on ultrasound: reproducibility, validity and normal range values. In: Book Measuring abdominal muscle function by abdominal muscle thickening on ultrasound: reproducibility, validity and normal range values

30. Valette X, Seguin A, Daubin C, Brunet J, Sauneuf B, Terzi N, du Cheyron D (2015) Diaphragmatic dysfunction at admission in intensive care unit: the value of diaphragmatic ultrasonography. Intensive Care Med 41:557-559

31. Winkler MH, Touw HR, van de Ven PM, Twisk J, Tuinman PR (2018) Diagnostic accuracy of chest radiograph, and when concomitantly studied lung ultrasound, in critically ill patients with respiratory symptoms: a systematic review and meta-analysis. Crit Care Med 46:e707-e714

32. McCool FD, Tzelepis GE (2012) Dysfunction of the diaphragm. N Engl J Med 366:932-942

33. Tobin MJ, Perez W, Guenther SM, Lodato RF, Dantzker DR (1987) Does rib cage-abdominal paradox signify respiratory muscle fatigue? J Appl Physiol 63(1987):851-860

34. Houston JG, Fleet M, Cowan MD, Mcmillan NC (1995) Comparison of ultrasound with fluoroscopy in the assessment of suspected hemidiaphragmatic movement abnormality. Clin Radiol 50:95-98

35. Chetta A, Rehman AK, Moxham J, Carr DH, Polkey MI (2005) Chest radiography cannot predict diaphragm function. Respir Med 99:39-44

36. Boussuges A, Bregeon F, Blanc P, Gil JM, Poirette L (2019) Characteristics of the paralysed diaphragm studied by M-mode ultrasonography. Clin Physiol Funct Imaging 39:143-149

37. Cohen E, Mier A, Heywood P, Murphy K, Boultbee J, Guz A (1994) Diaphragmatic movement in hemiplegic patients measured by ultrasonography. Thorax 49:890-895

38. Sanchez-Nicolas JA, Cinesi-Gomez C, Villen-Villegas T, Pinera-Salmeron P, Garcia-Perez B (2016) Relation between ultrasound-measured diaphragm movement and partial pressure of carbon dioxide in blood from patients with acute hypercapnic respiratory failure after the start of noninvasive ventilation in an emergency department. Emergencias 28:345-348

39. Cammarota G, Sguazzotti I, Zanoni M, Messina A, Colombo D, Vignazia GL, Vetrugno L, Garofalo E, Bruni A, Navalesi P, Avanzi GC, Della Corte F, Volpicelli G, Vaschetto R (2019) Diaphragmatic ultrasound assessment in subjects with acute hypercapnic respiratory failure admitted to the emergency department. Respir Care 64:1469-1477

40. Dos Santos Yamaguti WP, Paulin E, Shibao S, Chammas MC, Salge JM, Ribeiro M, Cukier A, Carvalho CR (2008) Air trapping: the major factor limiting diaphragm mobility in chronic obstructive pulmonary disease patients. Respirology 13:138-144

41. Antenora F, Fantini R, lattoni A, Castaniere I, Sdanganelli A, Livrieri F, Tonelli R, Zona S, Monelli M, Clini EM, Marchioni A (2017) Prevalence and outcomes of diaphragmatic dysfunction assessed by ultrasound technology during acute exacerbation of COPD: a pilot study. Respirology 22:338-344

42. Marchioni A, Tonelli R, Antenora F, Fantini R, Clini EM (2017) COPD exacerbation and diaphragmatic dysfunction: conditions with mutual influence influencing outcomes? Reply. Respirology 22:830-831

43. Heunks L, Ottenheijm C (2018) Diaphragm-protective mechanical ventilation to improve outcomes in ICU patients? Am J Respir Crit Care Med 197:150-152

44. Goligher EC, Fan E, Herridge MS, Murray A, Vorona S, Brace D, Rittayamai N, Lanys A, Tomlinson G, Singh JM, Bolz SS, Rubenfeld GD, Kavanagh BP, Brochard LJ, Ferguson ND (2015) Evolution of diaphragm thickness during mechanical ventilation impact of inspiratory effort. Am J Resp Crit Care 192:1080-1088

45. Schepens T, Dres M, Heunks L, Goligher EC (2019) Diaphragm-protective mechanical ventilation. Curr Opin Crit Care 25:77-85

46. McConville JF, Kress JP (2012) Weaning patients from the ventilator. N Engl J Med 367:2233-2239

47. Dres M, Goligher EC, Heunks LMA, Brochard LJ (2017) Critical illnessassociated diaphragm weakness. Intensive Care Med 43:1441-1452

48. Jung B, Moury PH, Mahul M, de Jong A, Galia F, Prades A, Albaladejo P, Chanques G, Molinari N, Jaber S (2016) Diaphragmatic dysfunction in patients with ICU-acquired weakness and its impact on extubation failure. Intensive Care Med 42:853-861

49. Dres M, Demoule A (2018) Diaphragm dysfunction during weaning from mechanical ventilation: an underestimated phenomenon with clinical implications. Crit Care 22:73

50. Kim WY, Suh HJ, Hong SB, Koh Y, Lim CM (2011) Diaphragm dysfunction assessed by ultrasonography: influence on weaning from mechanical ventilation. Crit Care Med 39:2627-2630

51. Mariani LF, Bedel J, Gros A, Lerolle N, Milojevic K, Laurent V, Hilly J, Troche G, Bedos JP, Planquette B (2016) Ultrasonography for screening and follow-up of diaphragmatic dysfunction in the ICU: a pilot study. J Intensive Care Med 31:338-343

52. Farghaly S, Hasan AA (2017) Diaphragm ultrasound as a new method to predict extubation outcome in mechanically ventilated patients. Aust Crit Care 30:37-43 
53. Lerolle N, Guerot E, Dimassi S, Zegdi R, Faisy C, Fagon JY, Diehl JL (2009) Ultrasonographic diagnostic criterion for severe diaphragmatic dysfunction after cardiac surgery. Chest 135:401-407

54. Llamas-Alvarez AM, Tenza-Lozano EM, Latour-Perez J (2017) Diaphragm and lung ultrasound to predict weaning outcome: systematic review and meta-analysis. Chest 152:1140-1150

55. Spadaro S, Grasso S, Mauri T, Dalla Corte F, Alvisi V, Ragazzi R, Cricca V, Biondi G, Di Mussi R, Marangoni E, Volta CA (2016) Can diaphragmatic ultrasonography performed during the T-tube trial predict weaning failure? The role of diaphragmatic rapid shallow breathing index. Crit Care 20:305

56. Palkar A, Narasimhan M, Greenberg H, Singh K, Koenig S, Mayo P, Gottesman E (2018) Diaphragm excursion-time index: a new parameter using ultrasonography to predict extubation outcome. Chest 153:1213-1220

57. Vivier E, Muller M, Putegnat JB, Steyer J, Barrau S, Boissier F, Bourdin G, Mekontso-Dessap A, Levrat A, Pommier C, Thille AW (2019) Inability of diaphragm ultrasound to predict extubation failure: a multicenter study. Chest 155:1131-1139

58. Zambon M, Greco M, Bocchino S, Cabrini L, Beccaria PF, Zangrillo A (2017) Assessment of diaphragmatic dysfunction in the critically ill patient with ultrasound: a systematic review. Intensive Care Med 43:29-38

59. Ferrari G, De Filippi G, Elia F, Panero F, Volpicelli G, Apra F (2014) Diaphragm ultrasound as a new index of discontinuation from mechanical ventilation. Crit Ultrasound J 6:8

60. DiNino E, Gartman EJ, Sethi JM, McCool FD (2014) Diaphragm ultrasound as a predictor of successful extubation from mechanical ventilation. Thorax 69:423-427

61. Heunks LM, van der Hoeven JG (2010) Clinical review: the ABC of weaning failure-a structured approach. Crit Care 14:245

62. Mayo P, Volpicelli G, Lerolle N, Schreiber A, Doelken P, Vieillard-Baron A (2016) Ultrasonography evaluation during the weaning process: the heart, the diaphragm, the pleura and the lung. Intensive Care Med 42:1107-1117

63. Tobin MJ, Jubran A, Laghi F (2001) Patient-ventilator interaction. Am J Respir Crit Care Med 163:1059-1063

64. Vaporidi K, Babalis D, Chytas A, Lilitsis E, Kondili E, Amargianitakis V, Chouvarda I, Maglaveras N, Georgopoulos D (2017) Clusters of ineffective efforts during mechanical ventilation: impact on outcome. Intens Care Med 43:184-191

65. Thille AW, Rodriguez P, Cabello B, Lellouche F, Brochard L (2006) Patientventilator asynchrony during assisted mechanical ventilation. Intens Care Med 32:1515-1522
66. Doorduin J, van Hees HW, van der Hoeven JG, Heunks LM (2013) Monitoring of the respiratory muscles in the critically ill. Am J Respir Crit Care Med 187:20-27

67. Soilemezi E, Vasileiou M, Spyridonidou C, Tsagourias M, Matamis D (2019) Understanding patient-ventilator asynchrony using diaphragmatic ultrasonography. Am J Resp Crit Care 200:E27-E28

68. Goligher EC, Laghi F, Detsky ME, Farias P, Murray A, Brace D, Brochard LJ, Bolz SS, Rubenfeld GD, Kavanagh BP, Ferguson ND (2015) Measuring diaphragm thickness with ultrasound in mechanically ventilated patients: feasibility, reproducibility and validity. Intensive Care Med 41:642-649

69. Yu CM, Sanderson JE, Marwick TH, Oh JK (2007) Tissue doppler imaging a new prognosticator for cardiovascular diseases. J Am Coll Cardiol 49:1903-1914

70. Maurizio R, Rinaldi VE, Camerini PG, Salvatori C, Leonardi A, Bini V (2019) Right diaphragmatic peak motion velocities on pulsed wave tissue doppler imaging in neonates: method, reproducibility, and reference values. J Ultrasound Med 38:2695-2701

71. Goldstone JC, Green M, Moxham J (1994) Maximum relaxation rate of the diaphragm during weaning from mechanical ventilation. Thorax 49:54-60

72. Oppersma E, Hatam N, Doorduin J, van der Hoeven JG, Marx G, Goetzenich A, Fritsch S, Heunks LMA, Bruells CS (2017) Functional assessment of the diaphragm by speckle tracking ultrasound during inspiratory loading. J Appl Physiol 123(1985):1063-1070

73. Goutman SA, Hamilton JD, Swihart B, Foerster B, Feldman EL, Rubin JM (2017) Speckle tracking as a method to measure hemidiaphragm excursion. Muscle Nerve 55:125-127

74. Bachasson D, Dres M, Nierat MC, Gennisson JL, Hogrel JY, Doorduin J, Similowski T (2019) Diaphragm shear modulus reflects transdiaphragmatic pressure during isovolumetric inspiratory efforts and ventilation against inspiratory loading. J Appl Physiol 126(1985):699-707

75. Vivier ERA, Doroszewski F, Roselli S, Pommier C, Carteaux G, Dessap AM (2019) Atrophy of diaphragm and pectoralis muscles in critically ill patients. Anesthesiology 131:569-579

76. Schepens T, Verbrugghe W, Dams K, Corthouts B, Parizel PM, Jorens PG (2015) The course of diaphragm atrophy in ventilated patients assessed with ultrasound: a longitudinal cohort study. Crit Care 19:422

77. Jiang JR, Tsai TH, Jerng JS, Yu CJ, Wu HD, Yang PC (2004) Ultrasonographic evaluation of liver/spleen movements and extubation outcome. Chest 126:179-185

78. Ueki J, Debruin PF, Pride NB (1995) In-vivo assessment of diaphragm contraction by ultrasound in normal subjects. Thorax 50:1157-1161 